\title{
Batı Karadeniz Bölgesinde Kuraklık Indisleri Üzerine Trend Analizi Uygulanması
}

\author{
Turgay Partal ${ }^{1, *} \oplus$, Ercan Yavuz ${ }^{1} \oplus$ \\ ${ }^{1}$ Ondokuz Mayıs Üniversitesi, Mühendislik Fakültesi, Inşaat Mühendisliği Bölümü, 55139 Atakum, Samsun.
}

\section{Özet}

Bu çalışmada Batı Karadeniz Bölgesinde elde edilen kuraklık indisleri üzerine trend analizi uygulanmıştır. Kuraklık, iklim araştırmacıları için son yıllarda çok önem verilen bir konu haline gelmiştir. Bu çalışma içinde, trend analizi yöntemleri kullanılarak, kuraklık indislerinde trend olup olmadı̆̆ araştırılmıştır. Trend analizi için ilk önce standart yağış indisi ve De martonne indisi elde edilmiştir. Daha sonra Mann-Kendall testi bu kuraklık indisleri üzerine uygulanmıştır. Çalışmada kullanılan veriler 1960 ve 2015 yılları arasında verilere sahip 6 istasyona aittir. Kullanılan veriler Batı Karadeniz Bölgesinin genel hidrolojik özelliklerini yansitacak şekilde seçilmiştir. Trend analizine göre, 1 aylık standart yağış indisi için Aşırı Şiddetli Kuraklık sinıfinda tüm istasyonlarda istatistiksel olarak \%5 anlamlllık seviyesinde önemli olmayan artan eğilim vardır. Diğer yandan De-Martonne indeksine göre kış aylarında ve yıllık olarak negatif z değerleri belirlenmiştir. Gözlenmiş yağışlarda trend belirlemek için yapılan araştırmada, Kasım, Aralık ve Ocak aylarında istasyonların çoğunda azalma eğilimleri belirlenmiştir.

\section{Anahtar Sözcükler}

Batı Karadeniz Bölgesi, De-Martonne İndisi, Standart Yağış İndisi, Trend Analizi

\section{Application of Trend Analysis on Drought Indices in the West Black Sea Region}

\begin{abstract}
This study has been carried out to trend analysis on drought indices in the West Black Sea Region. Drought is very important subject for climate researchers in recent years. In this study, it was investigated whether there is a trend in drought indices by using trend analysis methods. Firstly, the standardized precipitation index and De Martonne index were obtained for the trend analysis. After then, the Mann-Kendall test was applied to the drought indexes. The data network used in this study consists of 6 stations spanning from 1960 to 2015. The used data was selected to reflect general hydro-climatic conditions of the Western Black Sea Region. According to the trend analysis, there is an increasing trend that is not statistically significant at the 5\% significance level in all stations in the extremely severe drought class for the 1-month standard precipitation index. On the other hand, the negative $z$ values were determined in annual and winter De-Martonne indexes. The application of a trend detection in observed precipitations were resulted in the identification of decreasing trends in November, December and January precipitations for the mostly of stations.
\end{abstract}

$\underline{\text { Keywords }}$

West Black Sea, De-Martonne Index, Standardized Precipitation Index, Trend Analysis

\section{Giriş}

İklim olayları insan ve doğal yaşam üzerinde önemli etkilere sahiptir. Bu iklim olaylarından taşkın ve kuraklık son yıllarda önemli araştırma konularının başında gelmektedir. Kar ve yağmur gibi yağışlarda meydana gelen azalmanın kuraklığın önemli belirtilerinden olduğu kabul edilmektedir. Kuraklık genellikle kısa vadede değil, orta ve daha uzun vadelerde etkisini göstermektedir.

Literatürde meteorolojik kuraklık, hidrolojik kuraklık, tarımsal kuraklık ve sosyo-ekonomik kuraklık olmak üzere dört tip kuraklık tanımlanmaktadır (Şaylan vd. 1997). Kuraklık, meteorolojik kuraklık olarak başlar ve bunu sırasıyla tarımsal kuraklık ve hidrolojik kuraklık takip eder. Kuraklık, sosyo-ekonomik boyuta geldiğinde insan yaşamı üzerinde çok önemli etkiler meydana getirir. Bu yüzden bir bölgede kuraklığın gelecekte ne kadar etkili olabileceğinin belirlenerek gerekli önlemlerin alınması önem arz etmektedir.

Kuraklık üzerine yapılan araştırmalar genellikle kuraklık indisleri olarak tanımladığımız değişkenler yardımıyla yapılırlar. Günümüzde, standart yă̆ı̧̧ indisi, palmer indisi, z indisi, aridity indisi gibi pek çok kuraklık indisi tanımlanmaktadır. Ancak yalnızca yağış verilerine ihtiyaç duyması nedeniyle standart yağış indisi (SYİ), hesaplamasının kolay ve güvenli olması nedeniyle tüm dünyada en çok kullanılan kuraklık indisidir (Doğan vd. 2012). 
Standart yağış indisleri üzerine geçmişte pek çok çalışma yapılmıştır (Çaldağ 2004; Keskin vd. 2007; Petel vd. 2007; Topçuoğlu vd. 2008). Pamuk vd. (2004) Ege bölgesinde 14 yağış gözlem istasyonuna ait veri üzerine standart yağış indisi ile kuraklık analizi yapmışlardır. Gümüş vd. (2016) Şanlıurfa'da yağışların kuraklık analizini yine standart yağış indisi ile yapmışlar ve son 29 yılda kurak geçen ayların sayısının arttığını belirlemişlerdir. Selçuk (2017) tez çalışmasında, Kızılırmak havzasında SYİ değerlerini kullanarak kuraklık analizini yapmıştır. İrvem vd. (2018) Seyhan havzasında SYİ ve Run testi yöntemlerini kullanarak 3 ve 12 aylık periyotlarda kurak dönem analizi yapmışlar ve 4 yılda tekrarlayan kurak dönemleri belirlemişlerdir. De Martonne indisi de kuraklık analizinde kullanılan bir yöntemdir. Pellicone vd. (2019) İtalya'da Kurak bölgelerin belirlenmesi için De-Martonne indisini kullanmışlardır. Ali vd. (2017) De-Martonne ve Standart yağış indisini esas alan bir yöntem kullanarak Pakistan'a ait 17 istasyonda kuraklıkları araştırmışlardır. Nistor (2016) De-martonne indisi dahil olmak üzere dört farklı indis kullanarak kuraklıkları araştırmıştır.

Trend analizi iklim değişimin etkilerini araştırmak için kullanılan en önemli analizlerden biridir. Mann-Kendall testi trend analizinde en çok kullanılan ve parametrik olmayan bir işaret testidir. Türkiye'de ve Dünyada Mann-Kendall testi ile trend analizi için yağış ve sıcaklık verileri üzerine pek çok çalışma yapılııștır (Gocic ve Trajkovic 2013; Westra vd. 2013; Tian vd. 2017). Kahya ve Kalaycı (2003) Türkiye akımlarında trend analizini çalışmışlar ve özellikle Türkiye'nin batı bölgelerinde nehir akımlarında azalma trendleri belirlemişlerdir. Partal ve Kahya (2006) Türkiye yağışlarının Mann-Kendall yöntemiyle trend analizini araştırmışlar ve özellikle batı bölgelerinde olmak üzere önemli azalma trendleri belirlemişlerdir. Demir (2018) 19 istasyon verilerine yaptığı trend analizlerinin sonucunda; toplam yağışların, Batı Karadeniz Bölgesi'nde yer alan istasyonlarda azalırken, Orta ve Doğu Karadeniz Bölgesi'nde yer alan istasyonlarda arttığını tespit etmiştir. Bütün bu çalışmalar gözlenmiş veriler üzerine trend analizi yapmayı kapsamaktadır. Zhang vd. (2009) yaptıkları çalışmada Standart yă̆ı̧ indisi ve Aridity indisi ile hesaplanan kuraklık sınıflarına göre belirledikleri kuru ve yağışlı ayların sayısı üzerine Mann-Kendall yöntemi ile trend analizini Çin'in Pearl River havzasında uygulamışlardır. Bu çalışmayla Kuru ve yağışlı olarak sınıflandırdıkları ayların sayısının yıllar boyunca değişsimini belirlemişlerdir.

Bu çalışmada, Batı Karadeniz Bölgesinde bulunan illerdeki istasyonlara ait yağış ve sıcaklık verileri kullanılarak SYİ ve De Martonne kuraklık indis değerleri hesaplanmış daha sonra SYİ ve De Martonne kuraklık indisleri kullanılarak belirlenen kuraklık sınıflarının değişimleri de Mann-Kendall trend analizi yöntemi ile incelenmiştir. Bununla beraber gözlenmiş aylık ve yıllık yağışlarında trend analizi yapılmıştır. Ayrıca, SYİ ve De-Martonne kuraklık indislerinin sonuçları karşılaştırılmıştır.

\section{Materyal ve Metot}

\section{1. Çalışma Alanı ve Veriler}

Bu çalışmada Türkiye'nin Batı Karadeniz bölgesinde yer alan bazı istasyonlara ait aylık yağış verileri üzerine kuraklık analizi ve trend analizi yapılmıştır. Çalışmada kullanılan veriler Devlet Meteoroloji Genel Müdürlüğünden (MGM) temin edilmiş̧ir. Bu bölgede Karadeniz iklimi, iç kesimlerinde ise karasal iklim etkilidir. Kışları kıyı kesimlerde 1lık, iç kesimlerde ise soğuk ve karlıdır. Yazları kıyılarda 1 lık ve yağışlı, iç kesimlerde ise daha az yağı̧̧lıdır. Karadeniz Bölgesi’nde dağların kıyı kesimindeki nemli havanın iç kısımlara geçmesini engellediği için kıyı kesim ile iç kesim arasında önemli farklar görülür. Örneğin Zonguldak'ta yıllık toplam yağış $1218 \mathrm{~mm}$ seviyesinde iken, iç kesimde yer alan Bolu da 557 mm gibi düşük bir yıllık yağış vardır (Tablo 1). Karadeniz Bölgesi haritası ve kullanılan istasyonların dağılımı Şekil 1'de gösterilmiş̧ir.

Tablo 1: Istasyon bilgileri

\begin{tabular}{|l|c|c|c|c|c|}
\hline İstasyon Adı & İstasyon No & Veri Aralığı & $\begin{array}{c}\text { Yıllık Ortalama } \\
\text { Sıcaklık }\left({ }^{\circ} \mathrm{C}\right)\end{array}$ & $\begin{array}{c}\text { Toplam Yıllık Yağış } \\
\text { Ortalaması (mm) }\end{array}$ & Enlem - Boylam \\
\hline Bartın & 17020 & $1964-2015$ & 12.8 & 1040.90 & $41^{\circ} 37^{\prime} \mathrm{K}-32^{\circ} 21^{\prime} \mathrm{D}$ \\
\hline Bolu & 17070 & $1960-2015$ & 10.6 & 557.37 & $40^{\circ} 43^{\prime} \mathrm{K}-31^{\circ} 36^{\prime} \mathrm{D}$ \\
\hline Düzce & 17072 & $1962-2015$ & 13.3 & 821.13 & $40^{\circ} 50^{\prime} \mathrm{K}-31^{\circ} 08^{\prime} \mathrm{D}$ \\
\hline Karabük & 17077 & $1965-2013$ & 13.4 & 483.82 & $41^{\circ} 13^{\prime} \mathrm{K}-32^{\circ} 37^{\prime} \mathrm{D}$ \\
\hline Kastamonu & 17074 & $1960-2015$ & 9.8 & 499.27 & $41^{\circ} 22^{\prime} \mathrm{K}-33^{\circ} 46^{\prime} \mathrm{D}$ \\
\hline Zonguldak & 17022 & $1960-2015$ & 13.7 & 1218.34 & $41^{\circ} 26^{\prime} \mathrm{K}-31^{\circ} 46^{\prime} \mathrm{D}$ \\
\hline
\end{tabular}




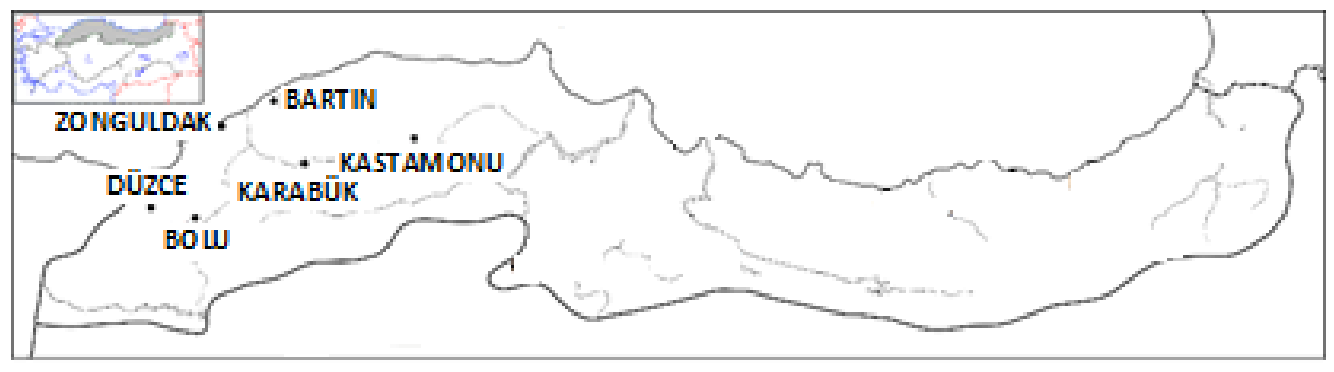

Şekil 1: Türkiye ve Karadeniz Bölgesi haritası

\subsection{Kuraklık İndisleri}

\subsubsection{Standart Yağış İndisi}

Standartlaştırılmış Yağış İndisi ilk olarak Mckee vd. (1993) tarafından ortaya atılmıştır. Standartlaştırılmış Yağış İndisi esas olarak belirlenen zaman dilimi içinde yağışın ortalamadan olan farkının standart sapmaya bölünmesi ile hesaplanır.

$S Y \dot{I}=\frac{X_{i}-\bar{X}}{\sigma}$

Burada $X_{i}$; aylık yağış miktarı, $\bar{X}$; uzun süreli aylık yağışların ortalaması, $\sigma$ ise yağış miktarlarının standart sapmasıdır. Genellikle 12 ay ve daha kısa periyotlarda yağış serileri normal dağılıma uymazlar. Bunun için SYİ değerlerinin normal dağılıma dönüştürülmesi gerekir. Bu prosedür için yağış serisini en iyi temsil eden Gamma dağılımı kullanılır. Yani aylık yağış frekansı dağılımına Gamma olasılık yoğunluk fonksiyonu uydurulur. Gamma olasılık yoğunluk fonksiyonu;

$g(x)=\frac{1}{\beta^{\alpha} \Gamma(\alpha)} x^{\alpha-1} e^{-x / \beta} \mathrm{x} \geq 0$

şeklinde hesaplanır. Burada $\alpha>0$ şekil parametresi, $\beta>0$ ölçek parametresi, $\Gamma(\alpha)$ Gama fonksiyonudur. Yine $\alpha$ ve $\beta$ 'nın tahmininde maksimum olasılık çözümlerini kullanılır (Anisfeld 2010). İlgili parametreler;

$A=\ln (\bar{x})-\frac{\sum \ln (x)}{n}$

$\alpha=\frac{1}{4 A}\left(1+\sqrt{1+\frac{4 A}{3}}\right)$

$\beta=\frac{\bar{x}}{\alpha}$

şeklinde hesaplanır. Burada, n: yağış gözlemlerinin sayısıdır. Eldeki mevcut verilerden elde edilen bu olasılık tanımlamaları daha sonra herhangi bir ayda gözlenmiş bir değerin kümülatif olasılığını bulmak için kullanılabilir. Bu durumda kümülatif olasılık dağılım fonksiyonu aşağıdaki şekilde tanımlanır.

$G(x)=\int_{0}^{x} g(x) d x=\frac{1}{\beta^{\alpha} \Gamma(\alpha)}=\int_{0}^{x} x^{\alpha-1} e^{-x} d x$

Gama fonksiyonu x= 0 için tanımsızdır ve yağış dağılımı sıfır (0) değerler içerebilir; bu durumda kümülatif olasılık dağılımı

$H(x)=q+(1-q) G(x)$

şeklinde hesaplanır. Yukarıdaki eşitlikte q sıfır değeri için olasılığı ifade eder. Eğer m herhangi bir yağış serisindeki sıfır (0) değerleri ifade etmek için kullanılırsa $q=m / n$ olarak tanımlanabilir. Kümülatif olasılık değeri H(x), ortalamas1 sıfir (0) ve bir (1) varyans değeri taşıyan, SYİ değerini ifade eden standart normal rastgele değerli Z değişkenine dönüştürülür (Selçuk 2017). H(x), SYİ'nin değeridir. SYİ yöntemine göre yapılan sınıflandırma Tablo 2'de verilmiştir (McKee vd. 1993; Gumus ve Algın 2017; Hangshing ve Dabral 2018). 
Tablo 2: SYİ değerlerinin sınıflandırılması

\begin{tabular}{|l|l|}
\hline SYİ Değerleri & Sınıflandırma \\
\hline 2.0 ve üstü & Çok Şiddetli Nemli \\
\hline $1.50-1.99$ arası & Şiddetli Nemli \\
\hline $1.00-1.49$ arası & Orta Şiddetli Nemli \\
\hline$-0.99-0.99$ arası & Normal \\
\hline$-1.00--1.49$ arası & Orta Şiddetli Kurak \\
\hline$-1.50--1.99$ arası & Şiddetli Kurak \\
\hline-2.00 ve altı & Çok Şiddetli Kurak \\
\hline
\end{tabular}

\subsubsection{De Martonne Kuraklık İndisi}

De Martonne indisi yıllık ortalama sıcaklık ve yıllık toplam yağış değerleri üzerine esas olacak şekilde belirlenir (De Martonne 1926). Buna göre Yıllık Kuraklık İndeksi $\left(I_{D M}\right)$ değerleri

$I_{D M}=\frac{P}{T+10}$

şeklinde hesaplanır. Burada $I_{D M}$; yıllık kuraklık indisi, P; yıllık toplam yağış $(\mathrm{mm})$ ve T; yıllık ortalama sıcaklıktır. De Martonne aylık kuraklık indis değeri ise

$I_{M}=\frac{12 P^{\prime}}{T^{\prime}+10}$

şeklinde hesaplanır. Burada $I_{M}$; aylık kuraklık indisi, $P^{\prime}$; aylık toplam yağıș $(\mathrm{mm}), T^{\prime}$; aylık ortalama sıcaklıktır. Bu formüllerde $\mathrm{T}$ ve $T^{\prime}$ değerlerine eklenen +10 değeri, bazı yerlerdeki negatif sıcaklık değerini pozitif yapmak için kullanılan bir katsayıdır.

De Martonne formülüne göre hesaplanan $I_{D M}$ ve $I_{M}$ değerleri için De Martonne kuraklık analizine göre sınıflandırma Tablo 3'te verilmiştir.

Tablo 3: De-Martonne kuraklık indisinin sınıflandırılması

\begin{tabular}{|c|c|}
\hline I $_{\mathrm{DM}}$ & İklim Özelliği \\
\hline $\mathrm{I}_{\mathrm{DM}}<5$ & Kurak \\
\hline $5 \leq \mathrm{I}_{\mathrm{DM}}<10$ & Yarı Kurak \\
\hline $10 \leq \mathrm{I}_{\mathrm{DM}}<20$ & Yarı Kurak - Yar1 Nemli Aras1 \\
\hline $20 \leq \mathrm{I}_{\mathrm{DM}}<30$ & Yar1 Nemli \\
\hline $30 \leq \mathrm{I}_{\mathrm{DM}}<60$ & Nemli \\
\hline $60 \leq \mathrm{I}_{\mathrm{DM}}$ & Çok Nemli \\
\hline
\end{tabular}

\subsection{Mann-Kendall Trend Testi}

Trend analizinde en çok kullanılan testlerin başında gelen Mann-Kendall testi parametrik olmayan bir işaret testtir. Bu test ile hidrometeorolojik zaman serilerinde var olabilecek pozitif veya negatif yöndeki eğilimlerin istatistiksel olarak önemli olup olmadığ belirlenir.

Parametrik olmayan testler değişkenlerin dağılımından etkilenmediği için verilerin değerlerinden ziyade işaretleri üzerine esastır. Veri setindeki her bir değerin, kendinden önceki değerlerin farkı alınır. Alınan bu değerlere işaret fonksiyonu uygulanır ve elde edilen -1 ve +1 'lerin toplamıyla S değeri elde edilir.

$S=\sum_{k=1}^{n-1} \sum_{j=k+1}^{n} \operatorname{sgn}\left(x_{j}-x_{k}\right)$

$\operatorname{sgn}\left(x_{j}-x_{k}\right)=\left\{\begin{aligned}+1 ; & \left(x_{j}-x_{k}\right)>0 \text { ise } \\ 0 ; & \left(x_{j}-x_{k}\right)=0 \text { ise } \\ -1 ; & \left(x_{j}-x_{k}\right)<0 \text { ise }\end{aligned}\right.$ 
$\mathrm{S}$ değerinin varyansı;

$\operatorname{Var}(S)=\frac{n(n-1)(2 n+5)}{18}$

şeklinde hesaplanır. Eğer veriler içerisinde benzer gözlemlerin olması durumunda $\mathrm{t}$ eşit olan gözlemlerin sayısını göstermek üzere S'nin varyans1;

$\operatorname{Var}(S)=\frac{n(n-1)(2 n+5)-\sum_{t} t(t-1)(2 t+5)}{18}$

ile hesaplanır. Mann-Kendall test istatistiğini gösteren, standart normal değişken z ise

$Z=\left\{\begin{array}{c}\frac{S-1}{\sqrt{\operatorname{Var}(S)}} ; S>0 \\ 0 ; S=0 \\ \frac{S+1}{\sqrt{\operatorname{Var}(S)}} ; S<0\end{array}\right.$

şeklinde hesaplanır. Mann-Kendall testinde kurulan hipotezler $\mathrm{H}_{0}$ ve $\mathrm{H}_{1}$ hipotezleridir. $\mathrm{H}_{0}$ hipotezi trendin olmadığını, $\mathrm{H}_{1}$ hipotezi ise trendin olduğunu belirtir. Yani seçilen bir $\alpha$ anlamlılık seviyesinde $|z| \leq z_{\alpha / 2}$ ise $\mathrm{H}_{0}$ hipotezi kabul edilir. $|z|>z_{\alpha / 2}$ ise $\mathrm{H}_{1}$ hipotezi kabul edilir. Bu çalışmada anlamlılık seviyesi olarak $\alpha=0.05$ olarak seçilmiştir. Standart Normal Dağılım tablosuna göre $z_{\alpha / 2}$ değeri 1.96 olarak bulunur. Mann-Kendall testine göre elde edilen $z$ değeri, [-1.96:1.96] aralığında ise $\mathrm{H}_{0}$ hipotezi kabul edilmiştir. Yani bu aralıkta bir $\mathrm{z}$ değerinin elde edilmesi halinde trendin olmadığ sonucuna varılır. Aksi halde $\mathrm{H}_{1}$ hipotezinin kabul edilir, bu durumda istatistiksel olarak önemli bir trend var demektir (Mondal vd. 2012).

\section{4.Çalışmada kullanılan metodoloji}

Bu çalışmada standart yağış indisi ve De-Martonne indisi kullanılarak trend analizi yapılması amaçlanmıştır. Bu amaçla ilk önce gözlenmiş yağış verileri kullanılarak 1, 3, 6 ve 12 aylık SYİ değerleri elde edilmiştir. Bu SYİ değerleri üzerinden Tablo 2 de verilen çeşitli sınıf aralıklarına düşen gözlem sayıları belirlenmiştir. Daha sonra bu gözlem sayılarının yıllık değişimini belirlemek için Mann-Kendall yöntemiyle trend analizi yapılmıştır. Böylece farklı SYİ sınıf aralıkları için trendler belirlenmiştir. SYİ ile elde edilen sonuçları kıyaslamak için gözlenmiş yağış ve sıcaklık verileri kullanılarak De-Martonne indis değerleri elde edilmiştir. Bu indislerin trend değişimi yine Mann-Kendall testi ile analiz edilmiş böylece iki farklı kuraklık indisinin trend sonuçları birlikte değerlendirilmiştir.

\section{Bulgular ve Tartışma}

\subsection{Standart Yağış İndisi (SYi) ile trend analizi}

Çalışmada ilk önce Batı Karadeniz bölgesinde yer alan 6 istasyonun aylık yağış verilerinden faydalanarak standart yağış indisleri elde edildi. Örnek olarak Zonguldak istasyonunun aylık yağış verilerinden elde edilen bir aylık SYİ değerlerinin zamansal değişimi Şekil 2‘de görülmektedir. SYİ değerleri genel olarak +2 ve -2 aralığında değişmektedir.

\section{Aylık SYi değerleri}

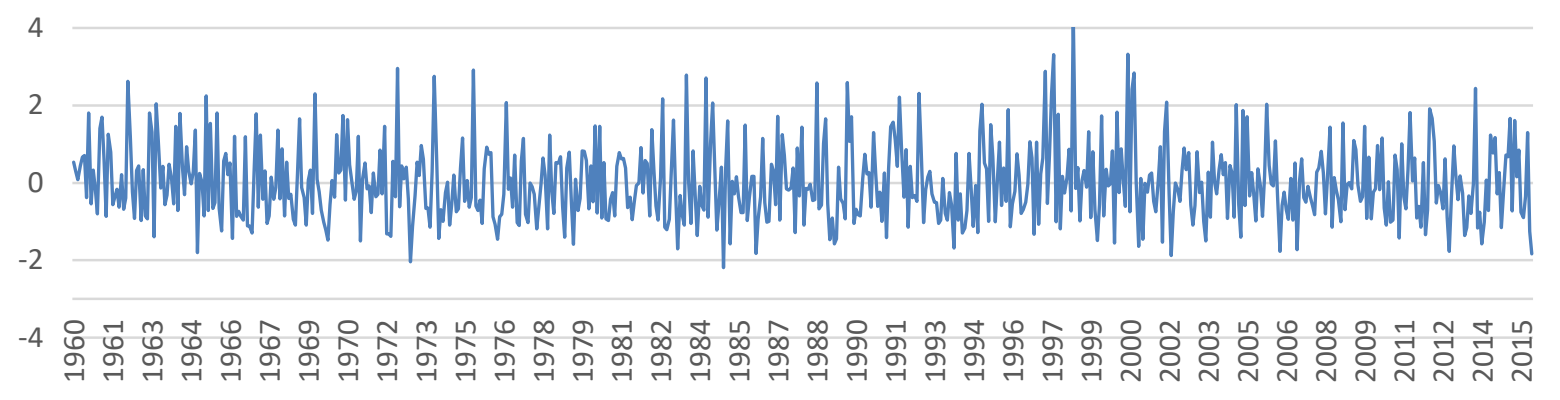

Şekil 2: 1 aylık SYi değerlerinin zaman grafiği 
Çalışmada daha sonra, 6 istasyon içinde elde edilen aylık SYİ değerleri kullanılarak Mann-Kendall trend analizi yapılmıştır. Bu amaçla ilk önce her ay için belirlenen SYİ değerlerinin, hangi sınıf aralığına düştüğü belirlenmiştir. Bu amaçla Tablo 2 kullanılmıştır. Daha sonra her yıl için sınıf aralıklarına düşen veri sayısının zamanla değişimi belirlenmiştir. Bu amaçla her sınıf aralığı için yıllara göre bulunan değerlerin üzerine Mann-Kendall testi uygulanmıştır. Elde edilen sonuçlar Tablo 4 de verilmiştir. Örnek olarak Zonguldak ili için Aşırı şiddetli kuraklık sınıfında gözlenen SYİ değerleri zamanla artış eğilimi göstermektedir $(z=1.75)$. Ancak Zonguldak ilinde 0.05 anlamlılık seviyesinde önemli bir trend bulunamamıştır. Genel olarak bakarsak, Aşırı Şiddetli Kuraklık sınıfında tüm istasyonlar için pozitif z değeri bulunmuştur. Bunun yanında Şiddetli ve Orta Şiddetli kuraklık sınıflarında çoğunlukla artış eğilimi (6 istasyonun 5 tanesinde) görülmektedir. Kastamonu ili için Aşırı Şiddetli Nemlilik sınıfında gözlenen SYİ değerleri istatistik olarak önemli artan bir trend göstermiştir $(\mathrm{z}=2.60)$. Bartın ili için ise Orta Şiddetli nemlilik sınıfında artış trendi $(\mathrm{z}=2.08)$, Aşırı Şiddetli Nemlilik sınıfında ise istatistiksel anlamlı azalma trendi bulunmuştur $(z=-2.13)$.

Tablo 4: 1 Aylık SYi değerlerine göre gözlenen kuraklık sınıflarının Mann-Kendall trend sonuçları

\begin{tabular}{|l|c|c|c|c|c|c|}
\hline İstasyon Adı & $\begin{array}{c}\text { Aşırı Şiddetli } \\
\text { Kuraklık }\end{array}$ & $\begin{array}{c}\text { Şiddetli } \\
\text { Kuraklık }\end{array}$ & $\begin{array}{c}\text { Orta Şiddetli } \\
\text { Kuraklık }\end{array}$ & $\begin{array}{c}\text { Orta Şiddetli } \\
\text { Nemlilik }\end{array}$ & $\begin{array}{c}\text { Şiddetli } \\
\text { Nemlilik }\end{array}$ & $\begin{array}{c}\text { Aşırı Şiddetli } \\
\text { Nemlilik }\end{array}$ \\
\hline Bartın & 0.30 & 0.49 & 0.36 & $\mathbf{2 . 0 8}$ & 0.89 & $\mathbf{- 2 . 1 3}$ \\
\hline Bolu & 0.29 & -0.03 & 0.69 & 1.13 & -1.52 & 0.85 \\
\hline Düzce & 0.58 & 0.58 & 0.49 & 0.62 & -1.33 & -0.67 \\
\hline Karabük & 0.81 & 0.78 & 1.18 & 0.92 & -0.10 & 0.18 \\
\hline Kastamonu & 0.02 & 1.13 & -0.11 & 0.41 & 0.53 & $\mathbf{2 . 6 0}$ \\
\hline Zonguldak & 1.75 & 0.00 & 0.76 & -0.82 & 0.31 & -0.63 \\
\hline
\end{tabular}

Çalışmada daha sonra, 6 istasyon için 3 aylık SYİ değerleri kullanılarak Mann-Kendall trend analizi yapılmıştır. Bu amaçla ilk önce aylık yağışlar kullanılarak 3 aylık SYİ değerleri belirlenmiş daha sonra 3 aylık belirlenen SYİ değerlerinin, hangi sınıf aralığına düştüğü belirlenmiştir. Elde edilen sonuçlar Tablo 5 de verilmiştir. Buna göre Aşırı Şiddetli Kuraklık sınıfında genel olarak yine artış eğilimleri belirlenmiştir. Zonguldak için Orta Şiddetli Nemlilik sınıfında gözlenen veri sayısında istatistiksel olarak önemli azalma trendi bulunmuştur ( $\mathrm{z}=-2.09)$. Aşırı Şiddetli Nemlilik sınıfı içinde 5 istasyonda artış eğilimi vardır.

Tablo 5: 3 Aylık SYi değerlerine göre gözlenen kuraklık sınıflarının Mann-Kendall trend sonuçları

\begin{tabular}{|l|c|c|c|c|c|c|}
\hline İstasyon Adı & $\begin{array}{c}\text { Aşırı Şiddetli } \\
\text { Kuraklık }\end{array}$ & $\begin{array}{c}\text { Şiddetli } \\
\text { Kuraklık }\end{array}$ & $\begin{array}{c}\text { Orta Şiddetli } \\
\text { Kuraklık }\end{array}$ & $\begin{array}{c}\text { Orta Şiddetli } \\
\text { Nemlilik }\end{array}$ & $\begin{array}{c}\text { Şiddetli } \\
\text { Nemlilik }\end{array}$ & $\begin{array}{c}\text { Aşırı Şiddetli } \\
\text { Nemlilik }\end{array}$ \\
\hline Bartın & -0.02 & 0.51 & 0.16 & 1.05 & 0.63 & -0.77 \\
\hline Bolu & 0.64 & -0.53 & -1.30 & 1.43 & -0.59 & 0.89 \\
\hline Düzce & 1.17 & 0.46 & 0.77 & -1.63 & -0.39 & 1.36 \\
\hline Karabük & 0.54 & -0.23 & 0.71 & -0.77 & 0.28 & 0.69 \\
\hline Kastamonu & 0.90 & -0.79 & -1.17 & 0.61 & 0.97 & 1.92 \\
\hline Zonguldak & 0.95 & 0.39 & 0.85 & $\mathbf{- 2 . 0 9}$ & -0.06 & 1.94 \\
\hline
\end{tabular}

Tablo 6: 6 Aylık SYI değerlerine göre gözlenen kuraklık sınıflarının Mann-Kendall trend sonuçları

\begin{tabular}{|l|c|c|c|c|c|c|}
\hline İstasyon Adı & $\begin{array}{c}\text { Aşırı Şiddetli } \\
\text { Kuraklık }\end{array}$ & $\begin{array}{c}\text { Şiddetli } \\
\text { Kuraklık }\end{array}$ & $\begin{array}{c}\text { Orta Şiddetli } \\
\text { Kuraklık }\end{array}$ & $\begin{array}{c}\text { Orta Şiddetli } \\
\text { Nemlilik }\end{array}$ & $\begin{array}{c}\text { Şiddetli } \\
\text { Nemlilik }\end{array}$ & $\begin{array}{c}\text { Aşırı Şiddetli } \\
\text { Nemlilik }\end{array}$ \\
\hline Bartın & -0.22 & 1.11 & -0.28 & 0.78 & 0.65 & 0.40 \\
\hline Bolu & 1.51 & 0.67 & -0.07 & 0.87 & 0.63 & 1.54 \\
\hline Düzce & 0.64 & 1.93 & 1.44 & -0.73 & -0.56 & 1.00 \\
\hline Karabük & 0.89 & -0.70 & 0.53 & -0.65 & 0.22 & -0.07 \\
\hline Kastamonu & -1.13 & -0.64 & -1.39 & 0.57 & $\mathbf{2 . 3 2}$ & 1.53 \\
\hline Zonguldak & 0.12 & 1.21 & 0.52 & $\mathbf{- 2 . 1 7}$ & 1.88 & 0.41 \\
\hline
\end{tabular}


Tablo 7: 12 Aylık SYİ değerlerine göre gözlenen kuraklık sınıflarının Mann-Kendall Trend sonuçları

\begin{tabular}{|l|c|c|c|c|c|c|}
\hline İstasyon Adı & $\begin{array}{c}\text { Așırı Şiddetli } \\
\text { Kuraklık }\end{array}$ & $\begin{array}{c}\text { Şiddetli } \\
\text { Kuraklık }\end{array}$ & $\begin{array}{c}\text { Orta Şiddetli } \\
\text { Kuraklık }\end{array}$ & $\begin{array}{c}\text { Orta Şiddetli } \\
\text { Nemlilik }\end{array}$ & $\begin{array}{c}\text { Şiddetli } \\
\text { Nemlilik }\end{array}$ & $\begin{array}{c}\text { Așırı Şiddetli } \\
\text { Nemlilik }\end{array}$ \\
\hline Bartın & -0.22 & 1.11 & -0.28 & 0.78 & 0.65 & 0.40 \\
\hline Bolu & 0.05 & 1.20 & 0.48 & -0.57 & 0.35 & $\mathbf{2 . 7 4}$ \\
\hline Düzce & 0.75 & $\mathbf{2 . 2 6}$ & 0.86 & -1.65 & -0.02 & 0.45 \\
\hline Karabük & -0.52 & 0.73 & 0.93 & -0.97 & 0.50 & 0.00 \\
\hline Kastamonu & -1.49 & -0.81 & 0.05 & 0.80 & 1.83 & 1.35 \\
\hline Zonguldak & 0.56 & -0.05 & 0.61 & 0.23 & 0.26 & 0.69 \\
\hline
\end{tabular}

Çalışmada daha sonra 6 aylık ve 12 aylık SYİ değerleri kullanılarak Mann-Kendall trend analizi yapılmıştır. Elde edilen sonuçlar Tablo 6 ve Tablo 7'de verilmiştir. Buna göre Aşırı Şiddetli Nemlilik sınıfında genel olarak artış eğilimleri vardır. 12 aylık SYİ için Bolu ilinde 0.05 anlam seviyesinde istatistik önemli pozitif trend belirlenmiştir $(z=2.74) .6$ ve 12 aylık SYİ için, Şiddetli Nemlilik sınıfında 1 istasyon hariç (Düzce) pozitif z değerleri yani artış eğilimleri vardır. Düzce istasyonunda 12 aylık SYİ için Şiddetli Kuraklık sınıfında artan trend belirlenmiştir. Aşırı Şiddetli Kuraklık sınıfı için bölgedeki istasyonlarda karışık bir görüntü olup genel bir eğilim belirlenmemiştir. İndislerin periyotlarındaki değişimlere bakıldığında ise ilginç sonuçlar vardır. Örneğin Aşırı Şiddetli Kuraklık sınıfında Zonguldak istasyonu 1 aylıkta $\mathrm{z}$ değeri 1.75 iken, 3 aylık için $\mathrm{z}$ değeri 0.95 e ve 12 aylık içinse 0.56 ya düşmüştür. 1 aylık için Aşırı Şiddetli Kuraklık sınıfında tüm istasyonlar pozitif $\mathrm{z}$ değeri verirken, 12 aylık için 3 istasyon pozitif $\mathrm{z}$ değeri vermiştir. Așırı Şiddetli Nemlilik için bakarsak, 1 aylık SYİ için 3 istasyon pozitif z değeri vermişken, 12 aylık SYİ için tüm istasyonlar pozitif z değeri vermiştir. Bu durum periyotlardaki değişimin trend sonuçlarında etkili olduğunu göstermektedir. Kisa periyotlarda kuraklık daha hakimken, uzun periyotlarda kuraklık etkisinin azaldığı görülmektedir.

Çalışmada ayrıca gözlenen yağışların aylık ve yıllık trendlerine de bakılmıştır (Tablo 8). Trend sonuçlarına bakıldığında Kasım ve Aralık aylarında 6 istasyonun 5 tanesinde, Ocak ve Şubat aylarında ise 6 istasyonun 4 tanesinde yağışlarda azalma eğilimi (negatif $\mathrm{z}$ değeri) görülmektedir. Ayrıca, Kasım ayında Karabük için $(\mathrm{z}=-2.25)$ ve Aralık ayında Düzce için $(\mathrm{z}=-2.17)$ istatistiksel anlamlı azalma trendi vardır. Yıllık yağışlara bakıldığında ise 3 istasyonda azalma eğilimi bulunmuştur. Haziran, Eylül ve Ekim yağışlarında ise tüm istasyonlarda artış eğilimi vardır.

Tablo 8: Tüm istasyonlara ait aylık bazda yağış verilerinin Mann-Kendall trend testi

\begin{tabular}{|c|c|c|c|c|c|c|c|c|c|c|c|c|c|}
\hline İstasyon Adı & Ocak & Şubat & Mart & Nisan & Mayıs & Haziran & Temmuz & Ağustos & Eylül & Ekim & Kasım & Aralık & Yıllık \\
\hline Bartın & 0.26 & -0.13 & 1.29 & -1.23 & -1.07 & 1.18 & 0.14 & -1.87 & 1.56 & 2.08 & -0.32 & -1.25 & 0.43 \\
\hline Bolu & -0.11 & 0.12 & 0.52 & 0.35 & -0.45 & 0.79 & -0.19 & -0.54 & -0.25 & 1.75 & -0.57 & -1.15 & 0.56 \\
\hline Düzce & -0.57 & -0.11 & -0.24 & -0.30 & -0.95 & 0.98 & -0.59 & -1.35 & 0.19 & 0.98 & -0.89 & -2.17 & -1.39 \\
\hline Karabük & -0.85 & -0.34 & 0.88 & 0.11 & -1.45 & 1.71 & -0.42 & -0.42 & 1.32 & 1.55 & -2.25 & -1.39 & -0.46 \\
\hline Kastamonu & 0.13 & -0.32 & 0.66 & -0.42 & 1.06 & 0.50 & 1.19 & 0.53 & 0.85 & 1.10 & 0.42 & 0.02 & 1.41 \\
\hline Zonguldak & -0.20 & 0.32 & 0.05 & -1.29 & -0.94 & 1.18 & -0.09 & -1.46 & 1.41 & 1.12 & -0.32 & -1.13 & -0.94 \\
\hline
\end{tabular}

\subsection{De Martonne Kuraklık indisi ile trend analizi}

Tüm istasyonlar için aylık ve yıllık bazda De Martonne kuraklık indis değerleri belirlenmiş daha sonra bu değerler üzerine Mann-Kendall testi uygulanmıştır. Elde edilen sonuçlar Tablo 9'da gösterilmiştir. Sonuçlara bakıldığında yıllık olarak 5 istasyon için azalma eğilimi belirlenmiştir. Bunlardan Düzce istasyonu istatistik önemli azalma trendi göstermiştir $(z=-2.24)$. Genel olarak bakıldığında yine kış ayları için negatif $z$ değerleri çok daha fazladır. Kasım ayında Karabük için istatistik önemli azalma trendi belirlenmiştir $(z=-2.08)$. Ekim ayında tüm istasyonlarda artış eğilimi vardır. Genel olarak De-Martonne indisinin sonuçları, gözlenmiş yağışların Mann-Kendall trend analizi sonuçları ile uyumludur. Ancak yıllık yağışlardaki azalma eğilimlerinin daha fazla olduğu görülmektedir. Sicaklık verilerinin de indis hesabına katılmasıyla bir miktar farklı değerler elde edildiği görülmektedir. 
Tablo 9: Aylık, yıllık de martonne kuraklık indislerinin Mann-Kendall trend analizi

\begin{tabular}{|c|c|c|c|c|c|c|c|c|c|c|c|c|c|}
\hline $\begin{array}{l}\text { İstasyon } \\
\text { Adı }\end{array}$ & Ocak & Şubat & Mart & Nisan & Mayıs & Haziran & Temmuz & A ğustos & Eylül & Ekim & Kasım & Aralık & Yıllık \\
\hline Bartın & -0.19 & -0.84 & 0.82 & -1.38 & -1.35 & 0.63 & -0.41 & -2.29 & 1.03 & 1.39 & -0.65 & -1.34 & -0.25 \\
\hline Bolu & -1.19 & -0.05 & 0.15 & -0.05 & -0.67 & 0.67 & -0.42 & -0.76 & -0.36 & 1.36 & -0.67 & -0.84 & -0.74 \\
\hline Düzce & -1.58 & -0.68 & -0.64 & -0.68 & -1.30 & 0.49 & -1.07 & -1.77 & -0.29 & 0.33 & -1.38 & -2.05 & -2.24 \\
\hline Karabük & -1.26 & -0.44 & 0.87 & 0.05 & -1.57 & 1.75 & -0.56 & -0.47 & 1.22 & 1.40 & -2.08 & -1.03 & -1.13 \\
\hline Kastamonu & -0.15 & -0.56 & 0.47 & -0.36 & 0.91 & 0.78 & 0.91 & 0.43 & 0.73 & 1.15 & 0.64 & 0.54 & 1.42 \\
\hline Zonguldak & -0.35 & 0.47 & -0.01 & -0.98 & -1.02 & 0.96 & -0.24 & -1.49 & 0.68 & 1.55 & -0.09 & -0.69 & -1.28 \\
\hline
\end{tabular}

De Martonne kuraklık indisine göre $\mathrm{I}_{\mathrm{DM}}<20$ olmak üzere kuraklık başladığı kabul edilir. Buna göre $\mathrm{I}_{\mathrm{DM}}<20$ olmak üzere yıl içinde belirlenen kurak ayların sayısının yıllar içerisindeki değişimini belirlemek için Mann-Kendall testi uygulanmıştır. Bulunan sonuçlar Şekil 3'te harita üzerinde gösterilmiştir. Sonuçlara bakıldığına kurak ayların sayısında 4 istasyon için artış eğilimi, 1 istasyon içinse azalma eğilimi belirlenmiştir. Örnek olarak Zonguldak istasyonu için $z=$ 1.18 bulunmuştur. Bu sonuç De-Martonne indisine göre kuraklığın daha belirgin olduğunu göstermektedir. Bunda sıcaklık değerlerinin etkisinin olduğu düşünülmektedir.

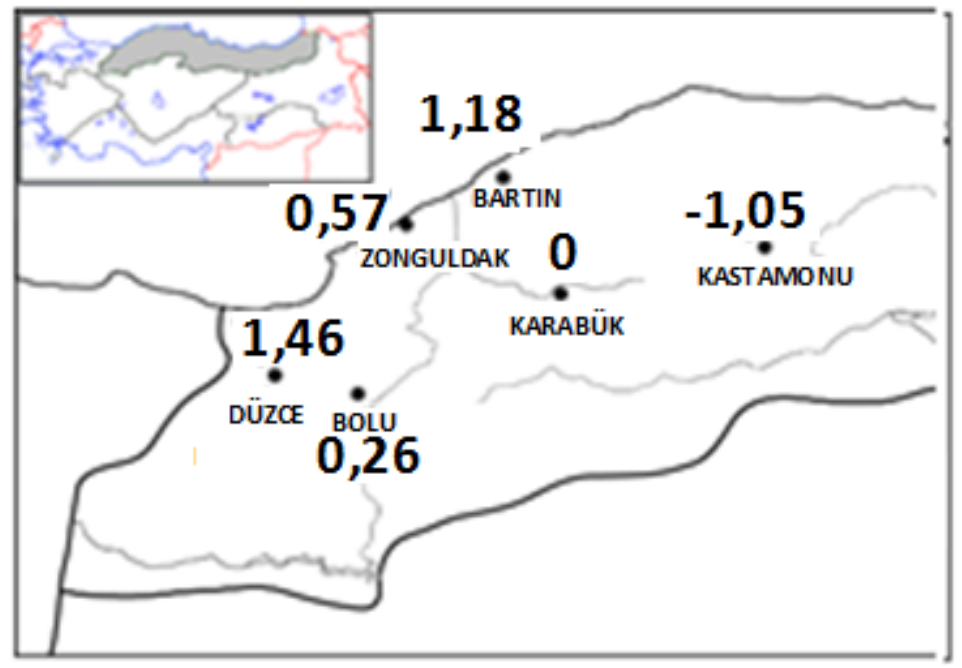

Şekil 3: Tüm istasyonlarda IDM<20 ayların sayısının trend analizi sonuçları

\section{Sonuçlar}

Bu çalışmada Batı Karadeniz Bölgesinde bulunan 6 istasyon için aylık yağış ve sıcaklık verileri kullanılarak, SYİ ve De Martonne indisleri hesaplanmıştır. Daha sonra bu indislerden belirlenen kuraklık sınıfları için Mann-Kendall yöntemi ile trend analizi yapılmıştır. Farklı periyotlardaki SYİ değerleri incelenerek farklar ortaya konmuştur. 1 aylık SYİ değerlerinin sınıf aralıkları üzerinde yapılan trend analizinde Aşırı Şiddetli Kuraklık sınıf aralığına düşen gözlemlerin sayısında tüm istasyonlarda istatistiksel önemli olmayan artış eğilimi belirlenmiştir. Ancak daha uzun periyotlar da genel olarak belirgin bir eğilim bulunamamıştır. Gözlenmiş yağışlara bakıldığında Kasım, Aralık ve Ocak aylarında Kastamonu hariç diğer istasyonlar için azalma eğilimi olmakla beraber Düzce istasyonunda Aralık ayında, Karabük istasyonunda ise Kasım ayında istatistiksel önemli azalma trendi bulunmuştur. De-Martonne indisi üzerine yapılan trend analizinde de $\mathrm{K}_{1}$ ş aylarında ve yıllık olarak bazı istasyonlarda azalma eğilimleri belirlenmiştir. Yıllık azalma eğilimlerinin gözlenmiş verilerin azalma eğilimlerine göre daha fazla olduğu belirlenmiştir. Ayrıca De Martonne indisine göre $\mathrm{I}_{\mathrm{DM}}<20$ olan kurak ayların sayısında genel olarak bir artış eğilimi görülmüştür. De Martonne kuraklık indisi hem yağış hem de sıcaklık verilerini birlikte kullanır. SYİ sadece yağış veri kullanılarak hesaplanan bir indistir. $\mathrm{Bu}$ sonuçlara göre sıcaklık verilerinin etkisi ile De-Martonne indisinin kuraklığı daha etkili gösterdiği düşünülebilir. Bu iki indisi bir arada kullanarak sadece yağış ve hem sıcaklık hem de yağışın kullanıldığı indisler arasındaki trend sonuçlarındaki farklılıklar ortaya konmuştur. 
Sonuçlar önceki çalışmalar ile kıyaslandığında da genel olarak uyumlu olduğu görülmektedir. Önceki çalışmalarda trend analizlerinin sonucunda; toplam yağışların, Batı Karadeniz Bölgesi'nde yer alan istasyonlarda azalırken, Orta ve Doğu Karadeniz Bölgesi'nde yer alan istasyonlarda arttı̆̆ belirlenmiştir (Saplıŏlu ve Çoban 2013; Demir 2018). Önceki çalışmalarda Düzce istasyonu için bulunan önemli azalma eğilimi bu çalışmada da De-martonne indisinin trend analizinde açıkça görülmektedir. Önceki sonuçlarla beraber bu çalışma bize Batı Karadeniz Bölgesinde Düzce gibi bazı istasyonlar için yağışlarda bir azalma eğilimini (özellikle kış ayları için) ve kuraklıkta artış olduğunu göstermektedir. Gelecek çalışmalarda farklı kuraklık indisleri ve farklı trend analizi yöntemleri kullanılarak kuraklığın daha detaylı analizin yapılması düşünülmektedir. Kuraklık indislerinin trend analizi bize kuraklığın belirlenmesinde daha net bilgiler sağlayabilecektir.

\section{Kaynaklar}

Ali Z., Hussain I., Faisal M., Nazir H.M., Abd-el Moemen M., Hussain T., Shamsuddin S., (2017), A Novel Multi-Scalar Drought Index for Monitoring Drought: The Standardized Precipitation Temperature Index, Water Resources Management, 31, 49574969.

Anisfeld S.C., (2010). Water Resources, Island Press, Washington DC, The United States of America, 352ss.

Çaldağ B., Şaylan L., Toros H., Sırdaş S., Bakanoğulları F., (2004), Drought analysis in northwest Turkey, Role of Multipurpose Agriculture in Sustaining Global Environment, 20 - 24, October, Udine, Italy, ss.169-179.

de Martonne E., (1926), Une nouvelle fanction climatologique: l'indice d'aridité. La Météorologie, 2, 449-458.

Demir V., (2018), Karadeniz Bölgesi yağışlarının trend analizi, Yüksek Lisans Tezi, Karatay Üniversitesi, Konya.

Doğan S., Berktay A., Singh V.P., (2012), Comparison of multi-monthly rainfall based drought severity indices, with application to semi-arid Konya closed basin, Turkey, Journal of Hydrology, 470- 471, 255-268.

Gocic M., Trajkovic S., (2013), Analysis of changes in meteorological variables using Mann-Kendall and Sen's slope estimator statistical tests in Serbia, Global and Planetary Change, 100, 172-182.

Gümüş V., Başak A., Oruç N., (2016), Standartlaştırılmış yağış indeksi (SYİ) yöntemi ile Şanlıurfa istasyonunun kuraklık analizi, Harran Üniversitesi Mühendislik Dergisi, 01(2016), 36-44.

Gumus V., Algın H.M., (2017), Meteorological and hydrological drought analysis of the Seyhan-Ceyhan River Basins, Turkey, Meteorological Applications, 24(1), 62-73.

İrvem A., Özbuldu M., Çıplak C., (2018), Seyhan Göksu-Himmetli alt-havzasının akım verileri ile kuraklık analizi. Journal of Agricultural Faculty of Mustafa Kemal University, 23(2), 148-157.

Hangshing L., Dabral, P.P., (2018), Multivariate Frequency Analysis of Meteorological Drought Using Copula, Water Resources Management, 32(5), 1741-1758.

Kahya E., Kalayci S., (2004), Trend analysis of streamflow in Turkey, Journal of Hydrology, 289(1-4), 128-144

Keskin M.E., Terzi Ö., Taylan E.D., Y1lmaz A.G., (2007), Isparta bölgesi meteorolojik kuraklık analizi, I. Türkiye İklim Değişikliği Kongresi (TIKKDEK), 11-13 Nisan İstanbul, ss.350-359.

McKee T.B., Doesken N.J., Kleist J., (1993), The relationship of drought frequency and duration to time steps, Preprints, 8th Conference on Applied Climatology, January 17-22, Anaheim, California, ss.179-184.

Mondal A., Kundu S., Mukhopadhyay A., (2012), Rainfall trend analysis by Mann Kendall test: A case study of NorthEastern part of Cuttack District, Orissa, International Journal of Geology, 2,70- 78.

Nistor M.M., (2016), Spatial distribution of climate indices in the Emilia-Romagna region, Meteorological Applications, 23, 304313.

Pamuk G., Özgürel M., Topçuoğlu K. (2004), Standart yağış indeksi (SPI) ile Ege bölgesinde kuraklık analizi. Ege Üniversitesi Ziraat Fakültesi Dergisi, 41(1), 99-106.

Partal T., Kahya E., (2006), Trend analysis in Turkish precipitation data, Hydrological Processes, 20, 2011-2026.

Pellicone G, Caloiero T., Guagliardi I., (2018), The De Martonne aridity index in Calabria (Southern Italy), Journal of Maps, 15(2), 788-796.

Petel N.R., Chopra P., Dadhwal V.K., (2007), Analyzing spatial patterns of meteorological drought using standardized precipitation index, Meteorological Applications, 14, 329-336.

Saplığlu K., Çoban E., (2013), Karadeniz bölgesi yă̆ıss serilerinin trend analizi, VII. Ulusal Hidroloji Kongresi 26 -27 Eylül, Süleyman Demirel Üniversitesi, Isparta, ss.500-512.

Selçuk D., (2017), Kızılırmak havzasında hidrometeorolojik parametrelerle kuraklık analizi ve tahmini, Yüksek Lisans Tezi, OMÜ Fen Bilimleri Enstitüsü, Samsun.

Şaylan L., Durak M., Şen O., (1997), Kuraklık ve etkileri, Meteorolojik Karakterli Doğal Afetler Sempozyumu, Bildiriler Kitabı, 7-9 Ekim, Ankara, ss.433-444.

Tian J., Liu J., Wang J., Li C., Nie H., Yu, F., (2017), Trend analysis of temperature and precipitation extremes in major grain producing area of China. International Journal of Climatology, 37(2), 672-687

Topçuoğlu K., Mengü G.P., Anaç S., (2008), Ege Bölgesi meteorolojik kuraklık analizi, 5. Dünya Su Forumu Türkiye Bölgesel Su Toplantıları-Konya Kapalı Havzası Yeraltısuyu ve Kuraklık Konferans1, 11-12 Eylül, Konya, Türkiye, ss.175-184.

Westra S., Alexander LV., Zwiers, F.W. (2013), Global increasing trends in annual maximum daily precipitation. Journal of Climate, 26, 3904-3918.

Zhang Q., Xu C.Y., Zhang Z., (2009), Observed changes of drought/wetness episodes in the Pearl River basin, China, using the standardized precipitation index and aridity index, Theoretical and Applied Climatology, 98, 89-99. 